\title{
LOCAL CONSOLE SYSTEM USING JAVA ON PERSONAL COMPUTERS FOR HIGH ENERGY ACCELERATORS
}

\author{
Noriichi KANAYA*, Seiji ASAOKA and Hideki MAEZAWA \\ Photon Factory \\ High Energy Accelerator Research Organization (KEK) \\ 1-1, Oho, Tsukuba, 305-0801, Japan
}

\begin{abstract}
A Local Console System has been designed and implemented using Java for high-energy accelerators. The Local Console System provides information on accelerator control operation in order to control and monitor the high-energy accelerator components. The system was implemented on PC computers running under WindowsNT. The system allows operating the accelerator as well as diagnosing the accelerator at any place in the field through the network. The system provides functionality of consoles either in the control room or, if a failure occurs in the accelerator, in the vicinity of the faulty accelerator component. The system can greatly reduce the shutdown time caused by a malfunctioned accelerator component. The design and implementation of the system is described.
\end{abstract}

\section{INTRODUCITON}

There are twenty-two synchrotron-radiation beam lines at the $2.5-\mathrm{GeV}$ positron storage ring, Photon Factory at the High Energy Accelerator Research Organization (KEK). These beam lines feed synchrotron radiation to the experimental hall where experiments, such as surface physics, x-ray lithography, microscopy and crystal structure analysis, are simultaneously carried out. These beam lines are simultaneously in operation, providing intense synchrotron-radiation beams. The pressures in the storage ring and the beam lines are maintained at an ultra-high vacuum (UHV) of less than $10^{-8} \mathrm{~Pa}$ to achieve a long beam lifetime, typically of more than sixty hours.

Consoles in the control room for high-energy accelerators generally tend to be large, heavy displays, $\mathrm{X}$-terminals and workstations. If there is a failure in the accelerator, it is useful to be able to locate any faulty component in the field, i.e., at the vicinity of the accelerator. Particularly, there are a number of users for a synchrotron radiation facility who use an intense photon beam for their experiment at the same time. Shutting down the accelerator caused by a malfunctioned device should be avoided as much as possible, even for a half day. Thus, the Local Console System has been designed and implemented.

\section{SYSTEM DESCRIPTION}

Figure 1 shows the configuration of the Local Console System. The Local Console system comprises an applet on World-Wide-Web (WWW) browser, a proxy server on an SGI UNIX workstation, and the operation server running on the control computer VAX/VMS.

In addition to Java's capability, due to its tight network-security mechanism than CGI, the Java Applet was chosen as the implementation language for the system. Needless to say, the Local Console System can be utilized on any WWW browser on a PC running WindowsNT4.0 that supports Java Applet. Due to the security restrictions of the WWW browser, the Applet is not allowed to make a direct link to the control system on the VAX in this case, except for the host (i.e., the UNIX workstation) from which the Applet is loaded. Thus, the server works as a proxy server. The http server is always listening to a TCP/IP port, and accepts a request from a WWW browser.

When invoked, the WWW browser on the PC loads the Java class library of the Local Console System from the http server on the UNIX workstation through the network. Then, the WWW browser automatically initiates the Local Console System. After being invoked, the Local Console System establishes a connection with the proxy server on the UNIX workstation across the network. As shown in Fig.2, the operator can specify operation information of the accelerator components to be concerned. The Local Console System composes a request message associated with the operator's choice. The packet includes a list of components and time information to be concerned. Then, the Local Console sends the request message to the proxy server on the UNIX workstation using a socket communication, and waits for a reply from the proxy server. Upon receiving the request, the proxy server relays it to the server on the VAX/VMS, inquiring status information on the

“Email:noriichi.kanaya@kek.jp 


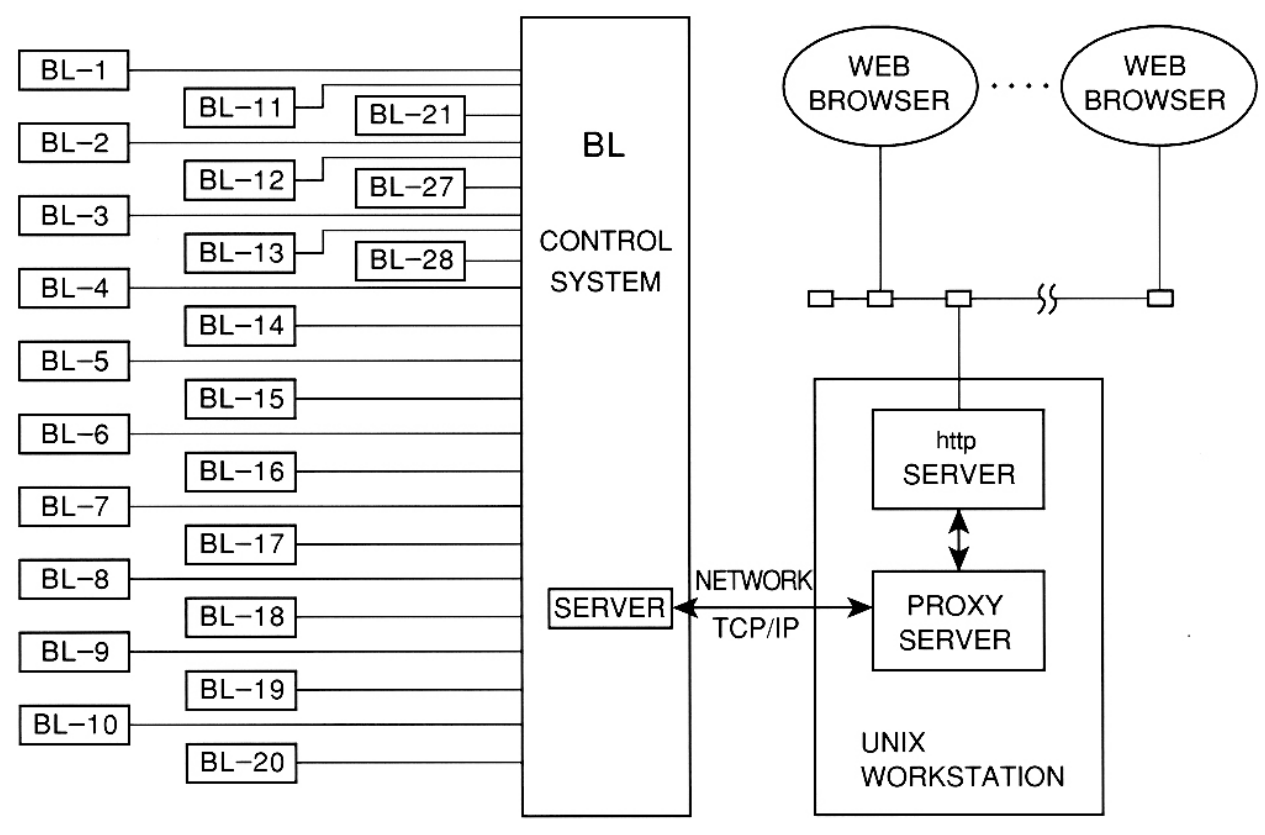

Fig1. Configuration of the Local Console System

accelerator components. After authenticating the contents of the request, the server at the VAX/VMS fetches operational information and control data from the control systems, for example, the control system for the synchrotron radiation beam lines [1][2].

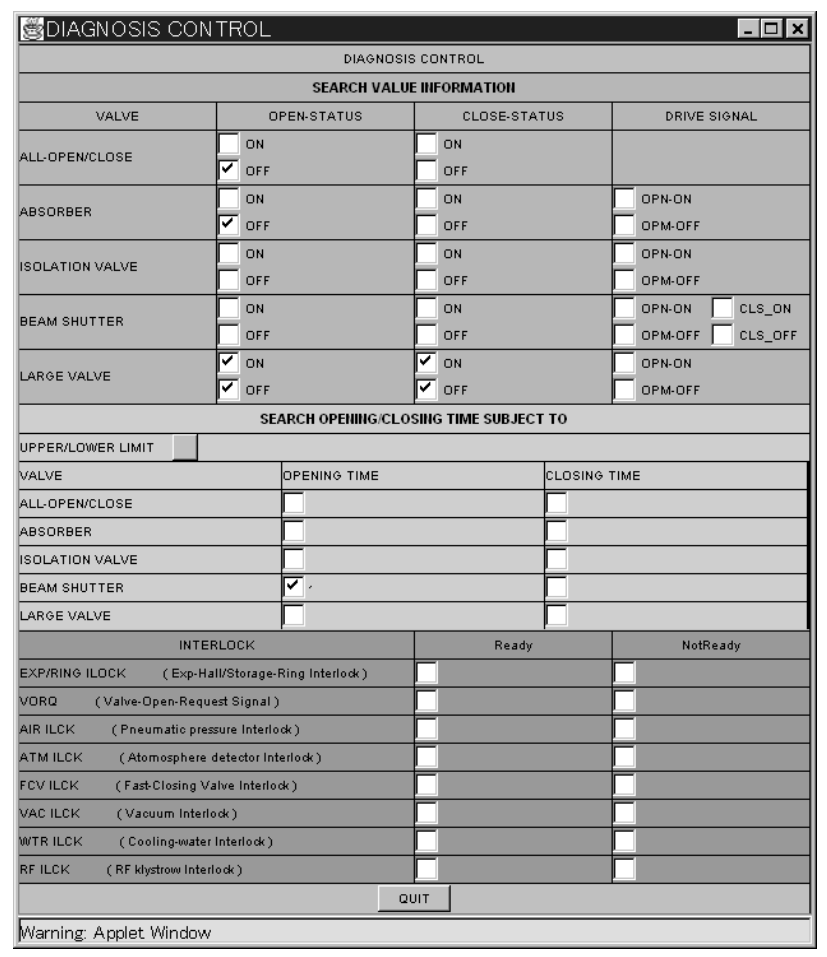

Fig. 2 A screen copy of the Local Console System.
The server replies to the proxy server by transmitting the operation information to the proxy server. The proxy server finally relays it to the Local Console System. The Local Console System can display the operational and control information on the WWW browser as the console screen. For security reasons, the proxy server accepts a request from PCs that have been registered to access.

The Local Console System also allows the operator to access the database on the control computer [3] in order to diagnose the accelerator when a failure occurs. Since a WWW browser on a lap-top computer can also invoke the Local Console System, it is possible to diagnose the accelerator at any place in the field through the network. The Local Console System provides functionality of consoles either in the control room or, if a failure occurs in the accelerator, the operator can diagnose the accelerator in the vicinity of the faulty accelerator component, making it possible to reduce shutdown time caused by the malfunctioned accelerator component.

Access to the database is carried out almost in the same way as normal access to the accelerator components, except for the role at the proxy server side. When the operator specifies operation information of the accelerator components to be concerned, the Local Console System composes a request message associated with the operator's choice. The packet includes a list of components and time information to be concerned. The Local Console System sends a request to the proxy server. The Local Console on the browser is waiting for the reply from the proxy server. Upon receiving a request, the server executes SQL statements to connect 
the on-line Oracle database running on the VAX/VMS. The communication between the two servers is done through an $\mathrm{SQL} *$ Net driver.

Once a connection is established, the server executes SELECT statements associated with the request submitted by the Local Console. After retrieving and collecting operational data of the accelerator components from the Database, the server transmits the operational information to the proxy server. After a completion message is sent back to the Local Console from the proxy server, it finally displays the operation information of the accelerator.

The Java environment is still evolving and growing rapidly. Since as of 1999 not all WWW browser supports Java RMI (Remote-Method-Invocation), we have implemented the Local Console using the Java Applet and the socket mechanism. This communication layer will be replaced by RMI. The VAX/VMS will be replaced by a UNIX workstation.

\section{CONCLUSION}

The Local Console System for accelerator components using Java Applet for high-energy accelerator components has been discussed. The system can obtain operational information of the accelerator components to allow inspecting the faulty accelerator component not only in the control room but also in the field.

\section{ACKNOWLEGEMENTS}

The authors wish to express their gratitude to the staff of the Photon Factory Light Source Division for operating the beam liens and the storage ring.

\section{REFERENCES}

[1] N.Kanaya, S.Sato, S.Asaoka, T.Koide and H.Maezawa, "Operational Experience with the Distributed Control System for Synchrotron Radiation Beam Lines at the Photon Factory", Particle Accelerators, Vol.29,pp.227-232,1990.

[2] N.Kanaya, S.Asaoka and H.Maezawa, "A Generic Model for Monitoring Operational Parameters of Accelerators by Heterogenesous Multiprocesses at the Photon Factory," Proc. of High Energy Accelerator Conference 1992, Hamburg, Germany, 1992.

[3] N.Kanaya, S.Asaoka and H.Maezawa, "Operational Logging System Using the Database for the Synchrotron Radiation Beam Lines at the Photon Factory," Proc. of Particle Accelerator Conference 1997, Vancouver, Canada, Mar. 1997. 